\title{
Rancang Bangun Games Pengenalan Fosil Purba Melalui Kartu Permainan Dengan Teknologi Augmented Reality
}

Fendi Aji Purnomo*1, Anggit Pangestu', Eko Wahyu Prasetyo ${ }^{1}$, Berliana Kusuma Riasti', Taufiqurrakhman Nur Hidayat', Ovide Decroly Wisnu Ardhi', Agus Purbayu ${ }^{1}$

'Program Studi D3 Teknik Informatika, Universitas Sebelas Maret, Surakarta, Jawa Tengah, Indonesia

*Email:fendi_ajimipa.uns.ac.id

\begin{tabular}{|c|c|}
\hline Info Artikel & Abstrak \\
\hline $\begin{array}{l}\text { Kata Kunci : } \\
\text { AR Game, fosil purba, android } \\
\text { Keywords : } \\
\text { AR Game, ancient fossils, android } \\
\\
\text { Tanggal Artikel } \\
\text { Dikirim : } 6 \text { September } 2019 \\
\text { Direvisi : } 5 \text { Oktober } 2019 \\
\text { Diterima : } 14 \text { November } 2019\end{array}$ & $\begin{array}{l}\text { Penelitian ini telah dilakukan rancang bangun pembuatan aplikasi games AR } \\
\text { yang bertujuan untuk mengenalkan fosil-fosil purba yang ada di ruang pamer } \\
\text { Museum Purbakala Sangiran. Metode yang digunakan dalam pembuatan } \\
\text { aplikasi game AR ini adalah Multimedia Development Life Cycle (MDLC) } \\
\text { dimulai dengan konsep, desain, material collecting, assembly, testing dan } \\
\text { distribution. Pembuatan Aplikasi Game Battle Card Museum Purbakala } \\
\text { Sangiran menggunakan Augmented Reality berbasis Android ini } \\
\text { menggunakan berbagai software yaituVuforia Developer untukmembuat fitur } \\
\text { marker, Vuforia SDK untuk mendapatkan ARCamera dan ImageTarget, } \\
\text { Unity3D untuk membuat Augmented Reality, Blender untuk pembuatan objek } \\
\text { 3D dan Corel Draw untuk membuat desain marker dan layout. Pengujian } \\
\text { game dilakukan secara black box, pengujian terhadap compatibilitas } \\
\text { perangkat dan pengujian hasil penilaian end user melalui kuisioner. Hasil } \\
\text { penelitian menyebutkan bahwa telah berhasil dibuat game AR pengenalan } \\
\text { fosil purba. Game tersebut minimal dapat berjalan pada perangkat dengan } \\
\text { minimal memori RAM } 2 \mathrm{~GB} \text {. Jarak ideal kamera mendeteksi kartu marker } 10 \\
\mathrm{~cm} \text { sampai dengan } 30 \mathrm{~cm} \text {. Sudut deteksi marker terhadap kamera antara } 30^{\circ} \\
\text { sampai dengan } 90^{\circ} \text {. Hasil penilaian mengenai tampilan visual game dinilai } \\
88.4 \% \text { menarik dan sangat menarik, model 3D yang disajikan } 84.6 \% \text { menarik } \\
\text { dan sangat menarik. }\end{array}$ \\
\hline
\end{tabular}

\begin{abstract}
Abstarct
This research aims to develop AR games application to introduce ancient fossils in the Sangiran Archaeological Museum showroom. The method used in making this AR game application is the Multimedia Development Life Cycle (MDLC) starting with the concept, design, material collecting, assembly, testing and distribution. The application of the Sangiran Archaeological Museum Battle Card Game using Android-based Augmented Reality uses a variety of software namely Vuforia Developer to create marker features, Vuforia SDK to get ARCamera and ImageTarget, Unity3D to make Augmented Reality, Blender for creating 3D objects and Corel Draw to create designs marker and layout. Game testing is done in a black box, testing the compatibility of the device and testing the results of the end user assessment through a questionnaire. The results of the study mentioned that the AR game was successfully made in the introduction of ancient fossils. The game can at least run on devices with a minimum of $2 G B$ RAM memory. The ideal distance of the camera to detect a marker card $10 \mathrm{~cm}$ up to $30 \mathrm{~cm}$. Marker detection angle of the camera is between 30 degrees to 90 degrees. The results of the assessment regarding the visual appearance of the game were rated $88.4 \%$ interesting and very interesting, the 3D model presented $84.6 \%$ interesting and very interesting.
\end{abstract}




\section{PENDAHULUAN}

Sangiran adalah sebuah situs purbakala yang mempunyai banyak sejarah kehidupan dan merupakan situs manusia purba yang terlengkap di Asia. Selain itu, Sangiran merupakan situs terpenting untuk perkembangan berbagai bidang ilmu pengetahuan terutama untuk penelitian di bidang antropologi, arkeologi, biologi, paleoantropologi, geologi, dan tentu saja untuk bidang kepariwisataan. Keberadaan Situs Sangiran sangat bermanfaat untuk mempelajari kehidupan manusia prasejarah karena situs ini dilengkapi dengan fosil manusia purba, hasil-hasil budaya manusia purba, fosil flora dan fauna purba beserta gambaran stratigrafinya. Satu hal yang dapat dipelajari di Situs Sangiran adalah hewan purba yang terdapat di Museum Sangiran. Situs Sangiran mengambil peranan penting dalam upaya menampilkan rekaman penemuan ilmiah. Namun, dalam hal penyajiannya masih menggunakan buku dengan ilustrasinya yang belum bersifat digital sehingga sukar dipahami dan kurang menarik. Hal tersebut bisa dikarenakan fosil yang ditemukan belum secara utuh atau dapat pula fosil kurang sempurna atau karena kurang menarik secara visual.

Perkembangan teknologi di Indonesia sendiri semakin pesat, hal ini karena turut didukung dengan perkembangan teknologi global yang juga semakin meluas. Penggunaan teknologi virtual reality [1]-[3]maupun augmented reality [4]-[6] dimana teknologi ini dapat menampilkan benda maya dua dimensi dan ataupun tiga dimensi ke dalam sebuah lingkungan nyata tiga dimensi lalu memproyeksikan benda-benda maya tersebut dalam waktu nyata. Dengan memanfaatkan augmented reality yang dikemas dalam sebuah aplikasi yang berisi tentang informasi benda-benda purbakala koleksi Museum Sangiran [7]-[9] diharapkan dapat menarik masyarakat atau wisatawan untuk cepat mendapatkan informasi secara langsung pada benda-benda purbakala yang ada di

Museum Sangiran serta memberikan hiburan lewat sebuah game battle pada teknologi augmented reality berbasis android tersebut. Konsep multimedia yang dikembangkan pada Museum Sangiran yaitu dengan teknologi Augmented Reality dan Virtual Reality [10]-[12]. Dalam penelitian ini bertujuan membuat aplikasi Augmented Reality untuk media hiburan dan edukasi dari macam-macam objek purbakala yang ada di Museum Purbakala Sangiran Ruang Pamer Satu agar lebih menarik dan interaktif. Objek purbakala tersebut berbentuk objek 3D dan akan ditampilkan menggunakan teknologi Augmented Reality di atas marker yang berbentuk kartu. Objek 3D tersebut nantinya bisa bertarung apabila terdapat dua objek 3D yang ditampilkan. Aplikasi ini juga memadukan teknologi Augmented Reality dengan campuran multimedia berupa audio dan animasi objek 3 dimensi sebagai aset pendukung agar aplikasi menjadi lebih menarik.

\section{METODE PENELITIAN}

Aplikasi Game Battle Card Museum Purbakala Sangiran menggunakan Augmented Reality ini berbasis android yang dapat digunakan sebagai media hiburan dan edukasi dari macam-macam objek purbakala yang ada di Museum Purbakala Sangiran Ruang Pamer Satu agar lebih menarik dan interaktif. Aplikasi ini menggabungkan objek dari dunia maya dan dunia nyata. Cara kerja aplikasi ini adalah, kamera smartphone menangkap input berupa marker. Kemudian pada layar smartphone akan muncul objek 3 dimensi. Apabila terdapat dua marker yang ditangkap oleh kamera maka dua objek 3 dimensi yang muncul tersebut bisa bertarung satu sama lain. Dalam aplikasi tersebut terdapat berbagai menu interaktif yang dapat digunakan untuk melihat informasi dari macam-macam objek purbakala yang ada di Museum Purbakala Sangiran.

Untuk pengembangan aplikasi ini metode yang digunakan adalah Multimedia Development Life Cycle (MDLC)[13], dimana metode ini memiliki 6 tahapan, yaitu concept, design, material collecting, assembly, testing dan distribution yang di tampilkan pada Gambar 1.

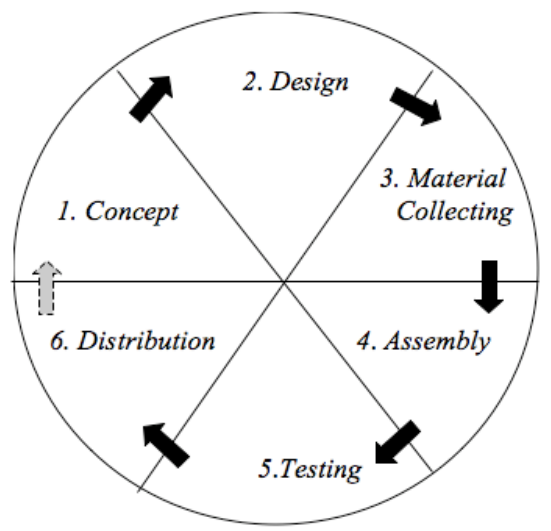

Gambar 1 Diagram Multimedia Development Life Cycle (MDLC) 
Concept, dalam tahapan ini ada beberapa tahapan yang perlu diperhatikan, antara lain Menentukan tujuan aplikasi yaitu untuk memberikan hiburan dan edukasi mengenai macam-macam objek yang ada di Museum Purbakala Sangiran Ruang Pamer Satu agar lebih menarik dan interaktif dengan menggunakan teknologi augmented reality berbasis android. Aplikasi ini dibuat menggunakan augmented reality pada perangkat android yang menggunakan kartu sebagai marker untuk menampilkan objek 3D dari macam-macam objek yang ada di Museum Purbakala Sangiran Ruang Pamer Satu serta dilengkapi dengan game battle di dalamnya. Deskripsi aplikasi Game Battle Card Museum Purbakala Sangiran menggunakan Augmented Reality ini berjalan dan dioperasikan pada perangkat bersistem operasi android.

Design, Pada tahapan ini dibuat spesifikasi aplikasi secara rinci dalam sebuah perancangan aplikasi. Dimana pembuatannya disesuaikan berdasarkan pada perancangan marker, perancangan objek 3 dimensi, perancangan interaktif (interactive design) dan perancangan antarmuka (interface design).

Material Collecting, Pada tahapan ini, materi yang terkait dengan aplikasi didapatkan dari mengumpulkan dokumen atau literatur tertulis, gambar, maupun data elektronik dari berbagai sumber seperti internet dan buku milik Balai Pelestarian Situs Manusia Purba Sangiran.

Assembly, Tahapan assembly (pembuatan) adalah tahapan dimana semua objek atau bahan multimedia dibuat. Semua objek atau material dibuat dan digabungkan menjadi satu aplikasi yang utuh. Dalam tahapan ini digunakan beberapa aplikasi perangkat lunak seperti, Vuforia, Unity 3D, Blender, dan Corel Draw.

Testing, Tahap ini disebut juga sebagai tahap pengujian alpha (alpha test) dimana pengujian dilakukan oleh pembuat atau lingkungan pembuatnya sendiri. Dalam pengujian aplikasi ini dilakukan pengecekan ketepatan benda berdasarkan marker. Pengujian selanjutnya adalah pengujian terhadap ketersediaan benda/obyek 3D dengan ukuran besar sehingga markertidak tersorot dengan baik. Pengujian selanjutnya dengan menggunakan pengujian kuisioner dengan responden masyarakat calon pengunjung dan pengunjung Museum Purbakala Sangiran.

Distribution, Dalam tahapan ini, aplikasi yang telah selesai diuji dan dinyatakan baik sesuai dengan tujuan pembuatan, akan didistribusikan dengan cara mengunggah ke sebuah toko online android.

\section{HASIL DAN PEMBAHASAN}

Pada aplikasi ini menggunakan 26 marker. Marker ini berfungsi untuk menampilkan objek 3 dimensi dari macam-macam objek purbakala yang ada di Museum Purbakala Sangiran. Tampilan splash screen digunakan untuk memberikan gambar awal ketika memulai aplikasi pertama kali. Gambar implementasi spalsh screen dapat dilihat pada Gambar 2.

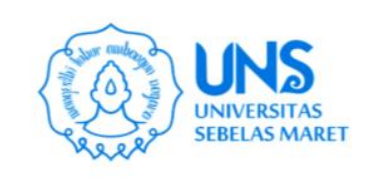

\section{Gambar 2. Implementasi Splash Screen}

Tampilan main menu merupakan tampilan menu yang di dalamnya terdapat 5 buttonyang digunakan untuk navigasi aplikasi. Button yang terdapat pada main menu antara lain button mulai, button galeri, button panduan, button tentang, dan button keluar. Gambar implementasi main menu dapat dilihat pada Gambar 3. 


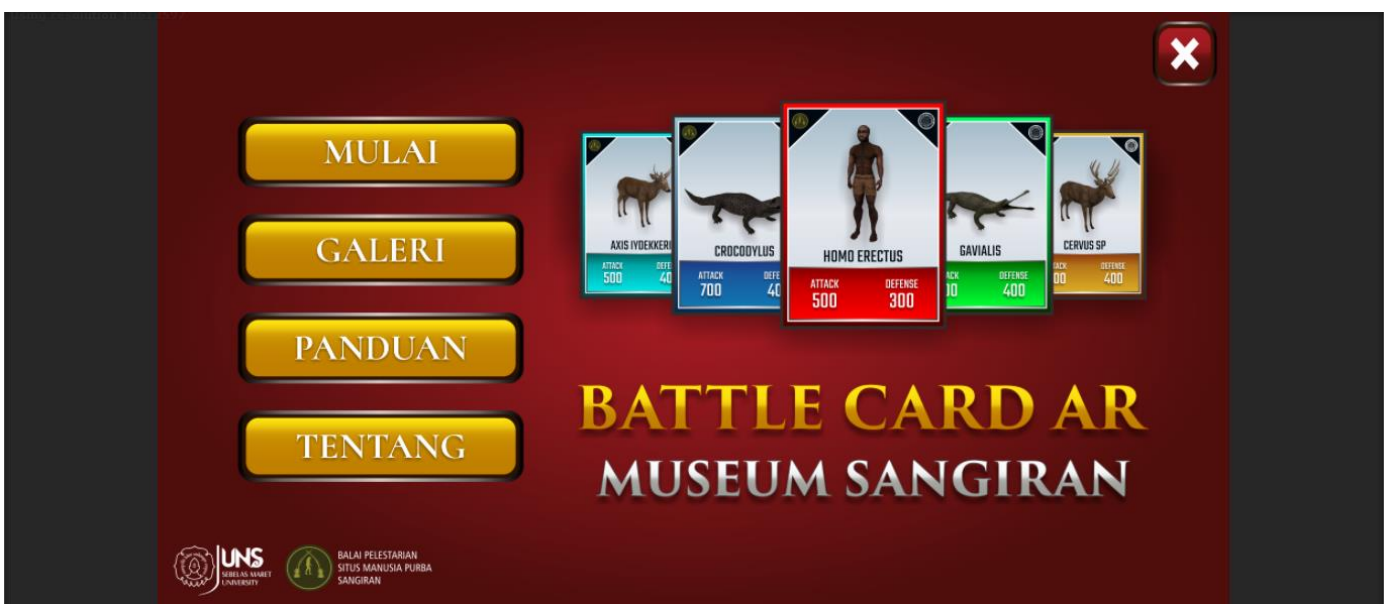

Gambar 3. Implementasi Main Menu

Tampilan gameplay menampilkan game battle objek 3D menggunakan augmented reality dengan cara memindai 2 marker yang telah dibuat melalui kamera pada smartphone yang dipakai. Gambar implementasi gameplay dapat dilihat pada Gambar 4.

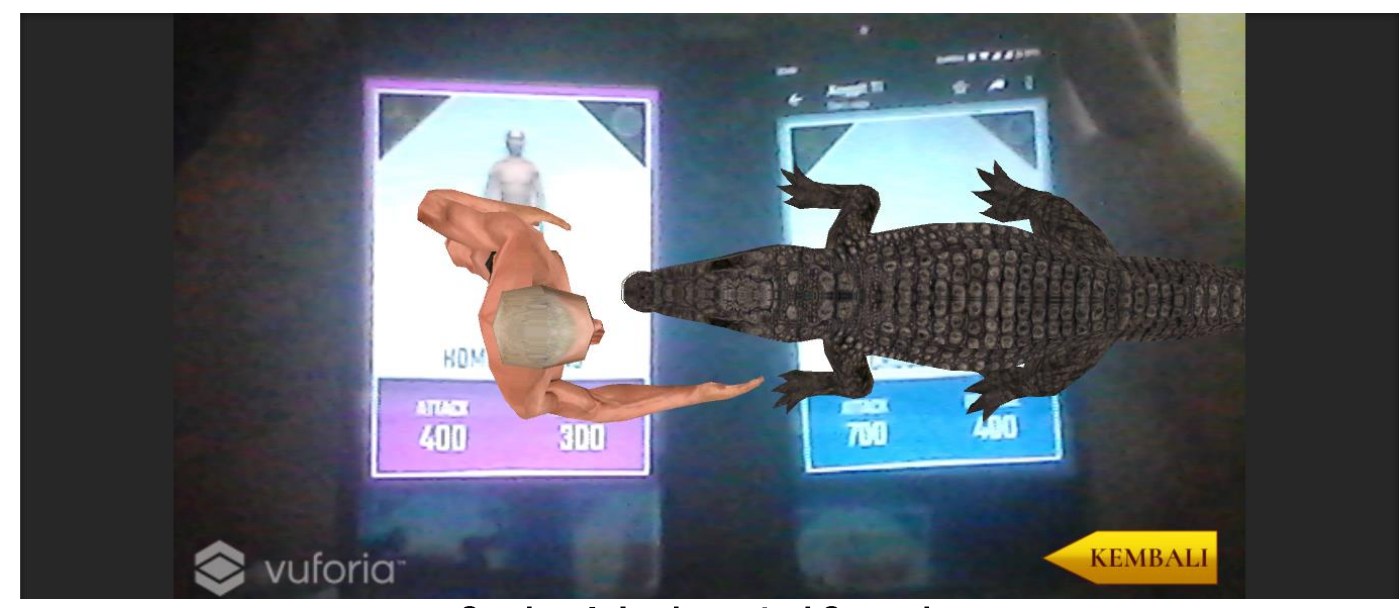

Gambar 4. Implementasi Gameplay

Tampilan menu galeri digunakan untuk menampilkan daftar dari objek 3D yang dibuat dalam bentuk 2D disertai dengan penjelasan singkat mengenai informasi objek tersebut. Gambar implementasi menu galeri dapat dilihat pada Gambar 5.

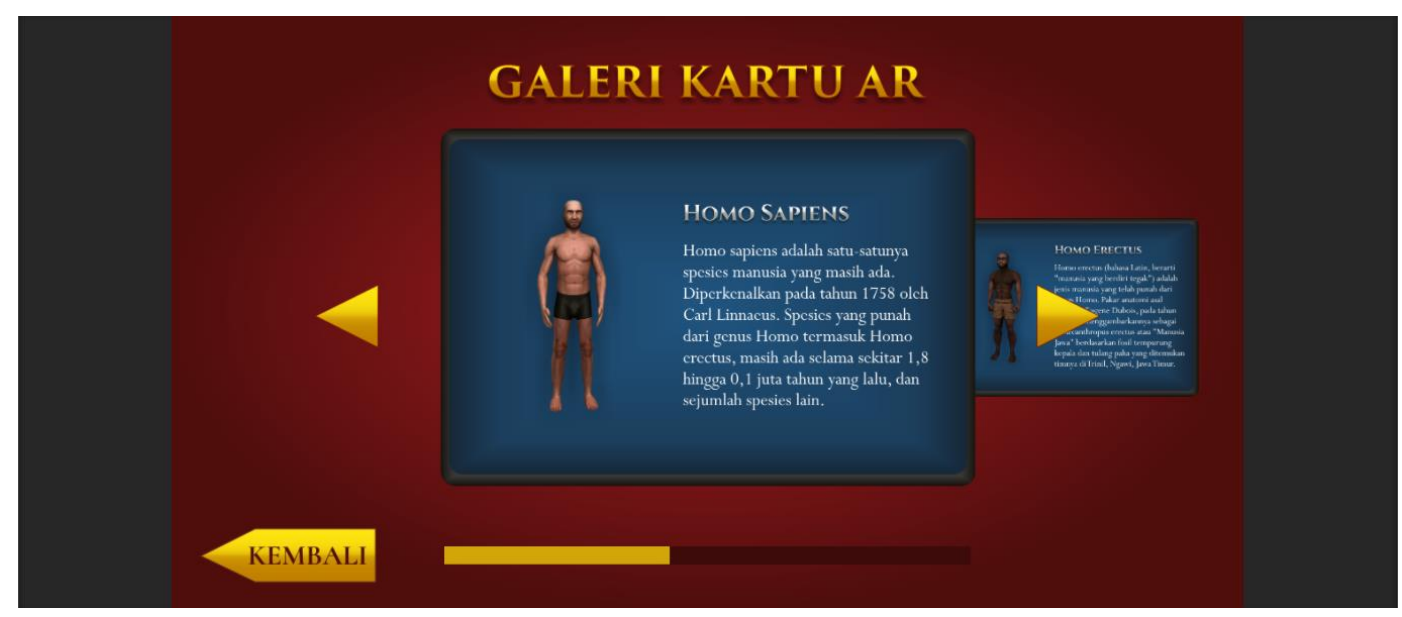

Gambar 5. Implementasi Menu Galeri 
Tampilan menu panduan digunakan untuk menampilkan petunjuk singkat dalam penggunaan aplikasi ketika memulai gameplayyang menampilkan game battle objek 3D menggunakan augmented reality. Gambar implementasi menu panduan dapat dilihat pada Gambar 6.

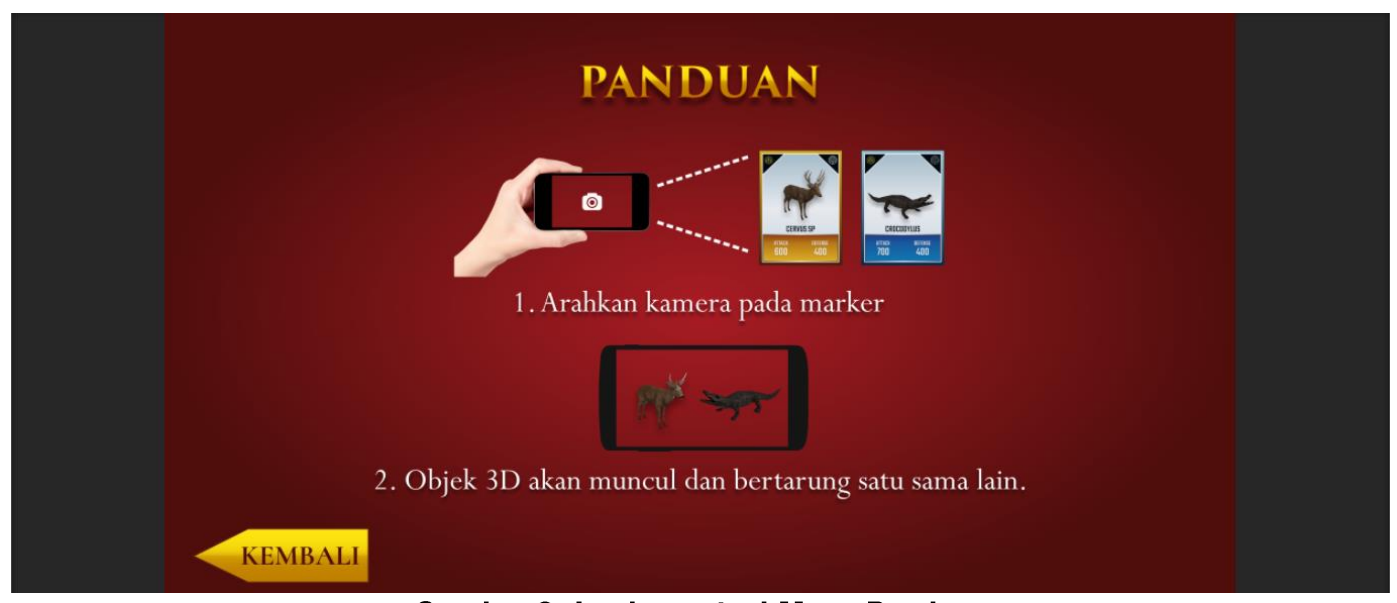

\section{Gambar 6. Implementasi Menu Panduan}

Tampilan menu tentang berisikan mengenai informasi aplikasi yang digunakan sebagai media hiburan dan edukasi dari macam-macam objek purbakala yang ada di Museum Purbakala Sangiran. Gambar implementasi menu tentang dapat dilihat pada Gambar 7.

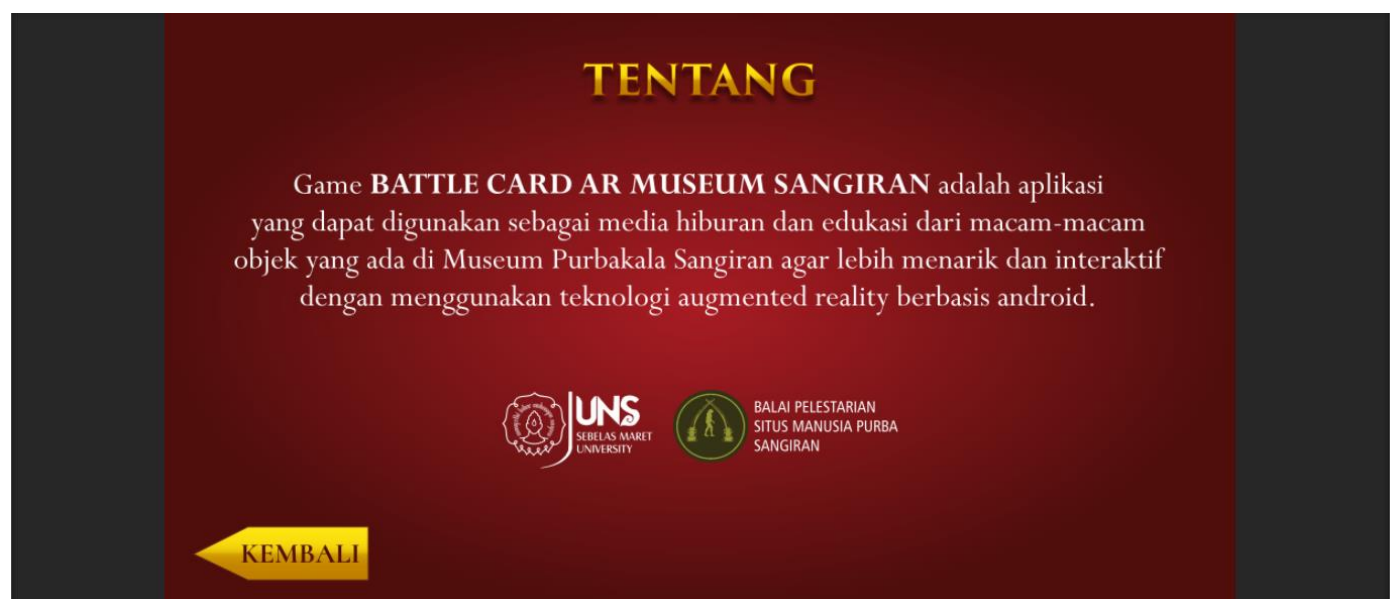

\section{Gambar 7. Implementasi Menu Tentang}

Pada tahap pengujian, dilakukan pengujian menggunakan metode blackbox testing. Metode blackbox testing adalah pengujian yang dilakukan hanya mengamati hasil eksekusi melalui data uji dan memeriksa fungsional dari perangkat lunak. Intinya hanya bisa melihat penampilan luarnya saja. Berikut ini adalah pengujian pada aplikasi Game Battle Card Museum Purbakala Sangiran menggunakan Augmented Realityyang disajikan ke dalam tabel-tabel pengujian sesuai fungsi-fungsi dalam aplikasi yang dapat dilihat pada Tabel 1 dan Tabel 2.

Tabel 1. Blackbox Testing 1

\begin{tabular}{ccccl}
\hline No & Jenis & Jenis & Tes & \multicolumn{1}{c}{ Keterangan } \\
\hline 1 & Scene & Splash screen & Sukses & $\begin{array}{l}\text { Splash screen muncul saat awal } \\
\text { aplikasi dijalankan }\end{array}$ \\
\cline { 3 - 5 } & Main Menu & Sukses & Muncul setelah splash screen \\
& & & \\
\hline
\end{tabular}




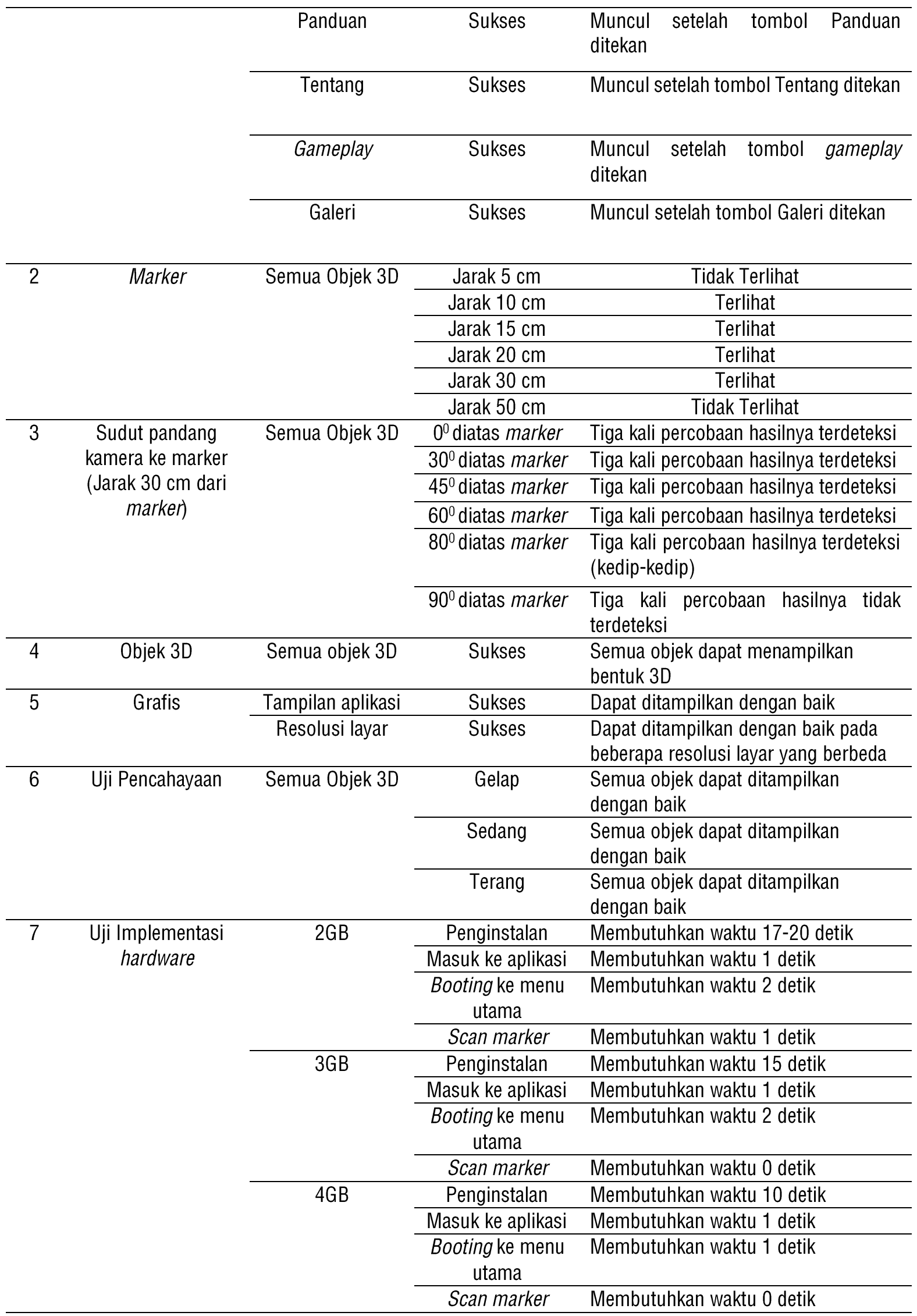




\begin{tabular}{ccccc}
\hline No & Komponen & Hasil yang diharapkan & Hasil Pengujian & Keterangan \\
\hline 1 & Tombol gameplay & $\begin{array}{c}\text { Memulai aplikasi AR untuk } \\
\text { menampilkan satu objek 3D, } \\
\text { dan apabila terdapat dua } \\
\text { objek 3D yang muncul maka } \\
\text { akan bertarung }\end{array}$ & $\begin{array}{c}\text { Dapat menampilkan satu } \\
\text { objek 3D, dan apabila } \\
\text { terdapat dua objek 3D yang } \\
\text { muncul dapat bertarung }\end{array}$ & Sukses \\
\hline 2 & Tombol Panduan & $\begin{array}{c}\text { Membuka halaman panduan } \\
\text { Dapat membuka halaman } \\
\text { panduan }\end{array}$ & Sukses \\
\hline 3 & Tombol Tentang & Membuka halaman tentang & $\begin{array}{c}\text { Dapat membuka halaman } \\
\text { tentang }\end{array}$ & Sukses \\
\hline 4 & Tombol Galeri & Membuka halaman Galeri & $\begin{array}{c}\text { Dapat membuka halaman } \\
\text { Galeri }\end{array}$ & Sukses \\
\hline 5 & Tombol Kembali & Menuju main menu & Dapat menuju ke main \\
menu & Sukses \\
\hline 6 & Tombol X & Aplikasi keluar & Dapat keluar dari aplikasi & Sukses \\
\hline
\end{tabular}

\section{Evaluasi}

Pada evaluasi aplikasi Game Battle Card Museum Purbakala Sangiran menggunakan Augmented Reality ini didasarkan pada hasil pengujian aplikasi dengan metode blackbox testing. Hasil dari pengujian aplikasi tersebut yaitu untuk menggunakan aplikasi Game Battle Card Museum Purbakala Sangiran menggunakan Augmented Reality ini, jarak ideal kamera mendeteksi marker adalah $10 \mathrm{~cm}$ sampai dengan $30 \mathrm{~cm}$. Sudut ideal untuk mendeteksi marker antara sudut $30^{\circ}$ sampai dengan sudut $90^{\circ}$ diatas marker.

\section{Kuisioner}

Hasil kusioner yang disajikan dalam bentuk presentase dan untuk lebih detailnya dapat dilihat dibawah ini.

1. Apakah anda pernah berkunjung ke Museum Purbakala Sangiran?
- Ya
$: 65,4 \%$
- Tidak
$: 34,6 \%$

2. Jika terdapat game yang menggunakan teknologi augmented reality apakah anda juga tertarik untuk berkunjung ?
- Sangat Setuju
$: 38,5 \%$
- Setuju
$: 53,8 \%$
- Cukup Setuju
$: 7,7 \%$
- Tidak Setuju
$: 0 \%$

3. Menurut anda bagaimana tampilan dari game yang kami buat. Apakah menarik ?
- Sangat Menarik
: $34,6 \%$
- Menarik
$: 53,8 \%$
- Cukup Menarik
$: 11,5 \%$
- Tidak Menarik
$: 0 \%$

4. Apakah game yang kami buat sulit untuk dimainkan?

- Sangat Mudah $\quad: 38,5 \%$
- Mudah : $61,5 \%$

- Tidak Mudah (Sulit) : $0 \%$

5. Menurut anda apakah model yang digunakan sudah sesuai ?

- Sangat Sesuai : $: 30,8 \%$

- Sesuai : :53,8\%

- Cukup Sesuai $: 15,4 \%$

- Tidak Sesuai $\quad: 0 \%$

6. Apakah gerakan dari model sudah sesuai dengan keadaan model ?

- Sangat Sesuai : $: 30,8 \%$

- Sesuai : $: 53,8 \%$

- Cukup Sesuai $: 15,4 \%$

- Tidak Sesuai : :0\%

7. Apakah tekstur yang digunakan sudah sesuai dengan objek?
- Sangat Sesuai
$: 42,3 \%$
- Sesuai
$: 46,1 \%$
- Cukup Sesuai
$: 11,5 \%$
- Tidak Sesuai

\section{KESIMPULAN}

Kesimpulan dari penelitian telah dihasilkan Game Battle Card Museum Purbakala Sangiran Ruang Pamer Satu Menggunakan Augmented Reality Berbasis Android" sebagai media hiburan dan edukasi. Game tersebut minimal dapat berjalan pada perangkat dengan minimal memori RAM 2GB. Jarak ideal kamera mendeteksi kartu marker $10 \mathrm{~cm}$ sampai dengan $30 \mathrm{~cm}$. Sudut deteksi marker terhadap kamera antara $30^{\circ}$ sampai dengan $90^{\circ}$. Hasil penilaian mengenai tampilan visual game dinilai $88.4 \%$ menarik dan sangat menarik, model 3D yang disajkan $84.6 \%$ menarik dan sangat menarik. 


\section{DAFTAR PUSTAKA}

[1] A. Sutcliffe, Multimedia and virtual reality: Designing multisensory user interfaces. 2003.

[2] T. Sunarni and D. Budiarto, "Persepsi Efektivitas Pengajaran Bermedia Virtual Reality ( VR )," vol. 2014, no. November, pp. 179-184, 2014.

[3] W. Ahmad, J. Wan, and A. Ahmad, "The effectiveness of signaling principle in virtual reality courseware towards achievement of transfer learning among students with different spatial ability The Effectiveness of Signaling Principle in Virtual Reality Courseware towards Achievement of Tra," 2017, vol. 020144, pp. 1-6.

[4] R. Azuma and R. Azuma, "A survey of augmented reality," Presence Teleoperators Virtual Environ., vol. 6, no. 4, pp. 355-385, 1997.

[5] M. Billinghurst and D. Schmalstieg, "Editorial : special issue on augmented reality," 2011.

[6] G. Margetis, X. Zabulis, and C. Stephanidis, "Augmented interaction with physical books in an Ambient Intelligence learning environment," 2012.

[7] Sutrima, Palgunadi, M. Yunianto, Sutanto, and F. A. Purnomo, "Evaluasi Penggunaan Aplikasi Museum Sangiran Berbasis Augmented Reality Dalam Menarik Minat Pengunjung," in Seminar Nasional Teknologi Informasi dan Multimedia 2014, 2014, pp. 1-6.

[8] F. A. Purnomo, "Pembuatan Mobile Tour Guide Museum Sangiran Dengan Augmented Reality Berbasis Markerless Tracking," SIMETRIS, vol. 6, no. 2, pp. 329-336, 2015.

[9] F. A. Purnomo, I. Santoso, and R. Hartanto, "2017," in International Conference on Advanced Materials for Better Future, 2017, pp. 1-6.

[10] F. A. Purnomo, E. H. Pratisto, and A. R. M. Putra, "2017," in AIP Conference Proceedings, 2017, vol. 1977, pp. $1-5$.

[11] F. A. Purnomo, E. H. Pratisto, and F. S. Bahtiar, "Design And Evaluation On The Immersive Virtual Reality System In Learning Archeology," in International Conference on Advanced Materials for Better Future 2018, 2018, pp. 1-4.

[12] F. A. Purnomo, E. H. Pratisto, A. Reza, and M. Putra, "Evaluation of serious game based on Bukuran Cluster of Museum Sangiran Evaluation of Serious Game Based on Bukuran Cluster of Museum Sangiran," in Human-Dedicated Sustainable Product and Process Design: Materials, Resources, and Energy, 2018, vol. 030014, no. June, pp. 1-5.

[13] A. C. Luther, Authoring Interactive Multimedia. Massachusettes: Academic Press, Inc., 1994. 